\title{
3D Transient CFD Modelling of Blood Flow through Coronary Artery
}

\author{
Lakumarapu Veena, K. Sai Krishna, T.Ch. Siva Reddy
}

\begin{abstract}
Over the past few decades, stroke has become one of the most common cause deaths. The heart muscle, like every other organ or tissue in our body, needs oxygen-rich blood to survive. Coronary artery disease means narrowing of the coronary arteries. This narrowing is due to a buildup of plaque in the walls of the arteries. Computational simulations provide invaluable information that is extremely difficult to obtain experimentally and is one of the many CFD sample applications in the biomedical area in which blood flow through an abnormal artery can be predicted. CFD analysis is increasingly performed to study fluid phenomena inside the human vascular system. In this paper, the study is to develop 3D CFD model of the Coronary artery to observe the blood flow through artery and estimate some of the hemodynamic parameters of blood during systolic and diastolic phase with plaque formation in artery. Hemodynamic parameters were quantified and flow patterns are visualized in the presence of plaques by using CFD.
\end{abstract}

Keywords: Coronary circulation, CAD disease, CFD, Coronary artery.

\section{INTRODUCTION}

Early hemodynamic investigations started with larger arteries were developed. Aorta has significant curved geometry and sites of branching similar to coronary arteries hence studies on aorta proved to be stepping stones towards the study of smaller and more curved coronary arteries. Hence, later these theories were implemented on coronary arteries. Coronary flow is different from the flow in the other parts of the arterial system because it is influenced by the contraction and relaxation of the heart. It is the pressure generated by the contraction of the heart muscles that give driving force for coronary circulation .Therefore, to model coronary flow and pressure realistically, it is necessary to have a model of the heart and a model of the arterial system. Plaque itself can pose a risk. A piece of plaque can break off and be carried by the bloodstream until it gets stuck. And plaque that narrows an artery also allows for the possibility that a blood clot (thrombus) may adhere to the blood vessel's inner wall. If either case, the artery can be blocked, cutting off blood flow. If the blocked artery supplies the heart or brain, a heart attack

Revised Manuscript Received on December 30, 2019.

* Correspondence Author

Lakumarapu Veena, M. Tech. Scholar, Department Of Mechanical Engineering, Sreenidhi Institute Of Science And Technology, Ghatkesar, Hyderabad, Telangana.

K. Sai Krishna, Associate Professor, Department Of Mechanical Engineering, Sreenidhi Institute Of Science And Technology, Ghatkesar, Hyderabad, Telangana.

T.Ch. Siva Reddy, Professor, Department Of Mechanical Engineering, Sreenidhi Institute Of Science And Technology, Ghatkesar, Hyderabad, Telangana.

(c) The Authors. Published by Blue Eyes Intelligence Engineering and Sciences Publication (BEIESP). This is an open access article under the CC BY-NC-ND license (http://creativecommons.org/licenses/by-nc-nd/4.0/) like aorta and theories linking WSS and plaque accumulation or stroke occurs.

If an artery supplying oxygen to the extremities (often the legs) is blocked, gangrene, or tissue death, can result. CFD modelling has already revolutionized research and development of devices such as stents, valve prostheses, and ventricular assist devices. Combined with cardiovascular imaging, CFD simulation enables detailed characterization of complex physiological pressure and flow fields and the computation of metrics which cannot be directly measured, for example, wall shear stress. CFD models are now being translated into clinical tools for physicians to use across the spectrum of coronary, valvular, congenital, myocardial and peripheral vascular diseases.

\section{GOVERNING EQUATIONS}

The simulation process involves solving a set of governing equations over a specified domain which is the coronary artery in this case. The governing equations include:

(1) Continuity equation

(2) Navier-stokes equations

I. Continuity Equation

$$
\frac{\partial u}{\partial x}+\frac{\partial v}{\partial y}+\frac{\partial w}{\partial z}=0
$$

\section{Momentum Equation (Navier-stokes Equation)}

$\mathrm{X}$-Momentum equation

$\rho\left(u \frac{\partial u}{\partial x}+v \frac{\partial u}{\partial y}+w \frac{\partial u}{\partial z}\right)=-\frac{\partial p}{\partial x}+\mu\left(\frac{\partial^{2} u}{\partial x^{2}}+\frac{\partial^{2} u}{\partial y^{2}}+\frac{\partial^{2} u}{\partial z^{2}}\right)$

Y -Momentum equation:

$\rho\left(u \frac{\partial v}{\partial x}+v \frac{\partial v}{\partial y}+w \frac{\partial v}{\partial z}\right)=-\frac{\partial p}{\partial y}+\mu\left(\frac{\partial^{2} v}{\partial x^{2}}+\frac{\partial^{2} v}{\partial y^{2}}+\frac{\partial^{2} v}{\partial z^{2}}\right)$

Z- Momentum equation:

$$
\begin{aligned}
\rho\left(u \frac{\partial w}{\partial x}+v \frac{\partial w}{\partial y}\right. & \left.+w \frac{\partial w}{\partial z}\right) \\
& =-\frac{\partial p}{\partial z}+\mu\left(\frac{\partial^{2} w}{\partial x^{2}}+\frac{\partial^{2} w}{\partial y^{2}}+\frac{\partial^{2} w}{\partial z^{2}}\right)
\end{aligned}
$$

\section{Non-Newtonian fluid models}

Blood is the major component of human circulatory system which is used as working fluid in this present analysis of blood flow. It comprises of concentrated suspension of several cellular elements,

\section{Published By:}




\section{D Transient CFD Modelling of Blood Flow through Coronary Artery}

RBCs and WBCs and platelets in aqueous solution. Some popular non-Newtonian models like Power law, and Carreau models are used to stimulate the blood behavior to different degrees of accuracy.

1. Power law model

Where $\eta_{0}=0.035$ and $n=0.6$

$$
\eta=\eta_{0} \gamma^{\mathrm{n}-1}
$$

\section{Carreau model}

$$
\eta=\eta_{\infty}+\left(\eta_{0}-\eta_{\infty}\right)\left[1+(\lambda \gamma)^{2}\right]^{n-1 / 2}
$$

Where the viscosity at high rate $\eta_{\infty}$ equals the value for the Newtonian model (i.e. $0.0035 \mathrm{~Pa}$ s) while the value at zero shear is $\eta_{0}=0.056 \mathrm{~Pa}$ s. Also: $\lambda=3.313 \mathrm{~s}$ and $\mathrm{n}=0.3568$.

\section{GEOMETRY CREATION}

For complex anatomical model, CT and MRI scan are preferable methods for geometry creation. The cardiac computed tomography angiography scanned image of coronary artery geometry used in this project got from the other source mentioned in references. The image data of the patient is first converted into a 3D model and then a solid CAD model is extracted through the process of reverse engineering.

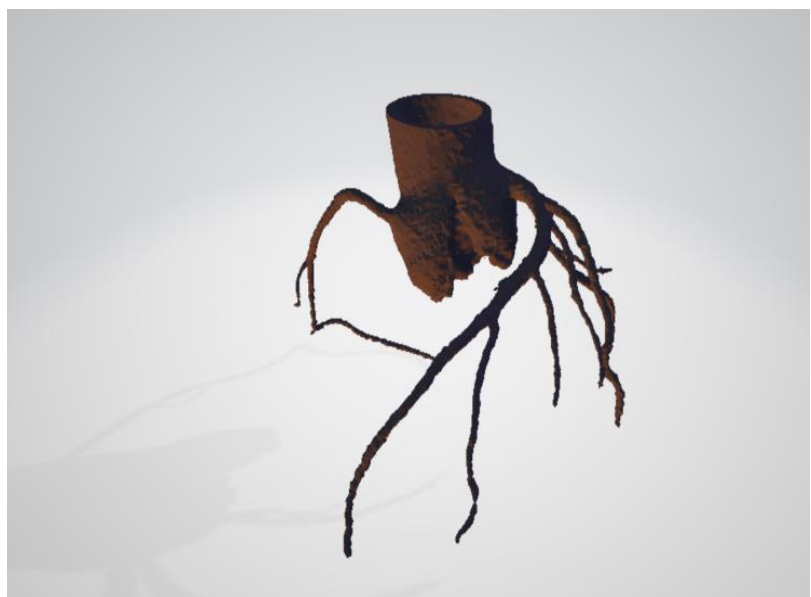

Fig.1.CT scan image of coronary artery

Since this 3D model had irregularities on its surface, it was needed to be smoothened before extracting the solid CAD model. This was done using Blender. Blender is a free and open-source 3D computer graphics software toolset used for 3D printd models, Visual effects and 3D applications.

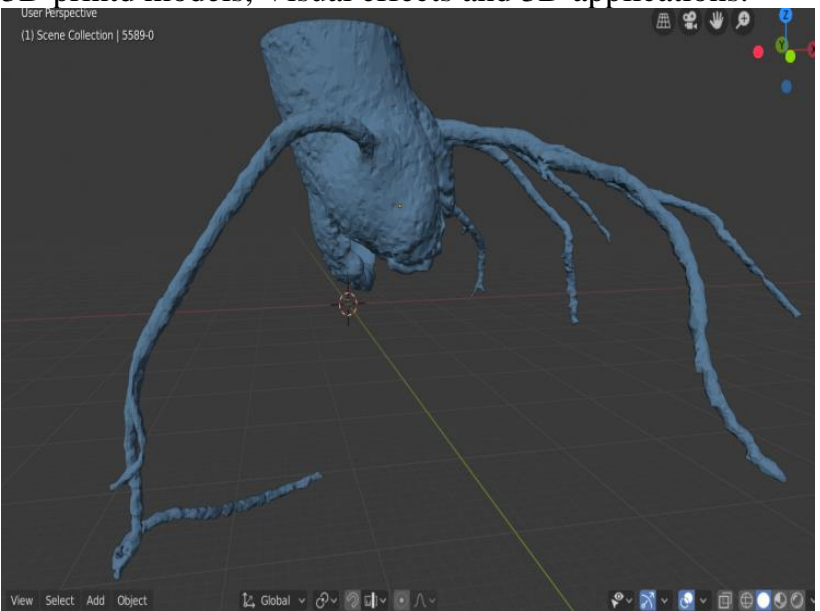

Fig.2.Coronary artery before smoothening

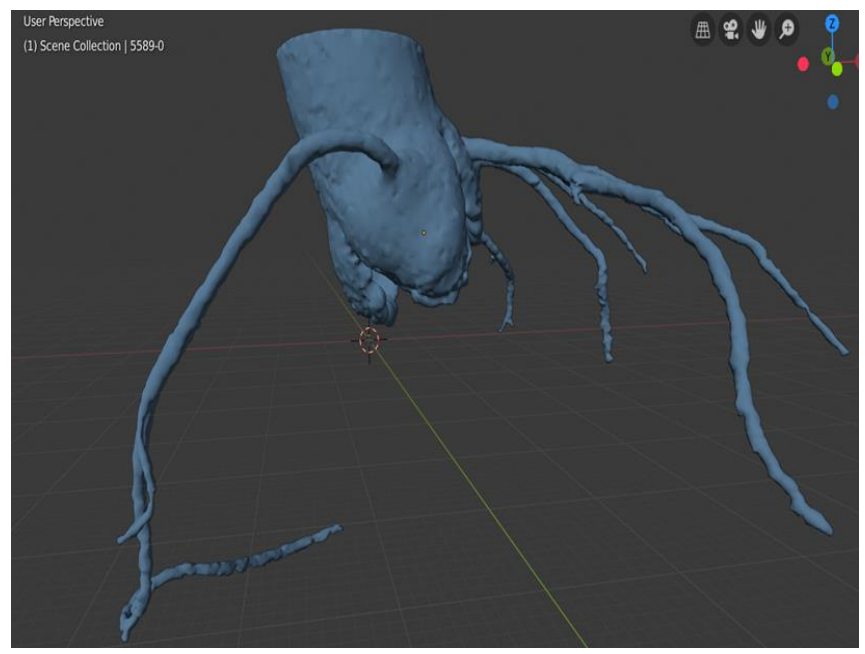

Fig.3.Coronary artery after smoothening

Then this geometry was imported to ANSYS SpaceClaim for convert to CAD model. This was done by using reverse engineering process. Using skin surface tool in ANSYS SpaceClaim, several faces were created on the surface of the body and after filling faces, solid model was generated.

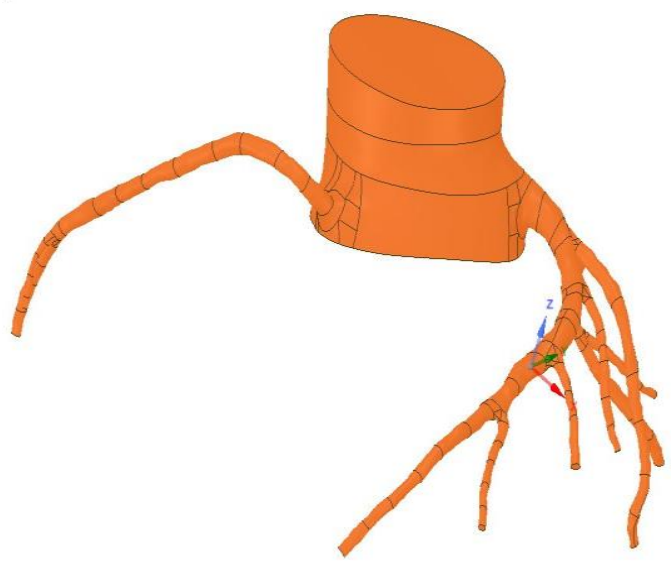

Fig.4.Geometry

\section{MESHING}

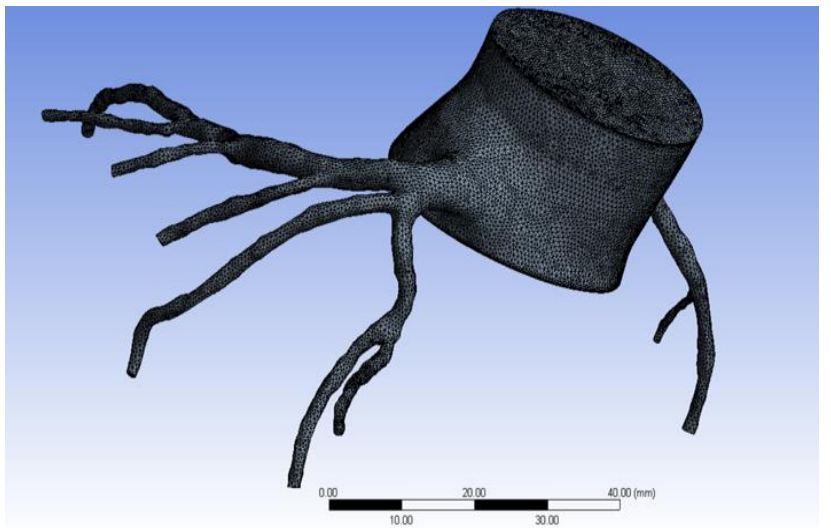

Fig.5. Mesh

The geometry is meshed by using Inflation meshing for better understand of flow. Inflation meshing was done by using Transition Ratio $=0.272$

Maximum Layers $=5$

Growth Rate $=1.2$ 
Meshing was done by using Element size is $0.5 \mathrm{~mm}$ and generate the mesh. The mesh of the geometry consists of 334101 elements. After generating meshing give name selections to the geometry of the artery. The named selections are inlet and LCA outlet and RCA outlet and aorta outlet.

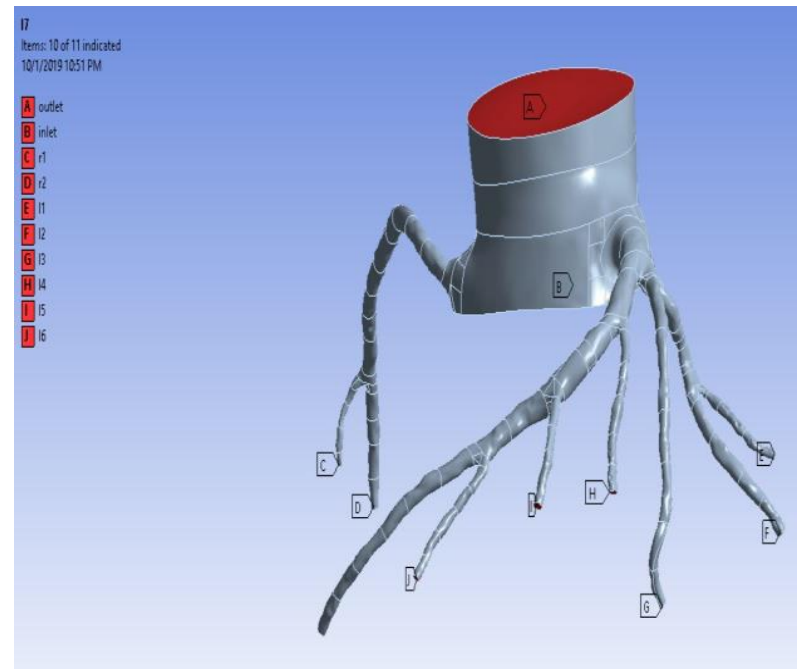

Fig.6. Naming selections of the geometry

The geometry has inlet and aorta outlet along with two right coronary outlets and seven left coronary outlets.

\section{SETUP AND FLOW SPECIFICATIONS}

To solve governing equations, some assumptions such as blood was considered incompressible and non-Newtonian fluid. The equations are solved for a steady state flow with no-slip boundary conditions at all the inlet and outlet boundaries..

Power law model

$$
\eta=n_{0} \gamma^{\mathrm{n}-1}
$$

Where $\eta_{0}$ is the zero-shear rate viscosity and $\mathrm{n}$ is a dimensionless parameter.

$\begin{array}{ll}\text { Zero shear rate limit }\left(\mathrm{\eta}_{0}\right) & 0.035 \mathrm{~Pa}-\mathrm{s} \\ \text { Relaxation time constant }(\gamma) & 3.313 \mathrm{~s} \\ \text { Power law index }(\mathrm{n}) & 0.6 \\ \text { Blood specific hear capacity } & 3617 \mathrm{~J} \mathrm{Kg}^{-1} \mathrm{k}^{-1} \\ \text { Blood conductivity } & 0.52 \mathrm{~W} \mathrm{M}^{-1} \mathrm{k}^{-1} \\ \text { Density } & 1060 \mathrm{Kg} / \mathrm{m}^{3}\end{array}$

\section{BOUNDARY CONDITIONS}

\section{Steady State}

Apply the boundary conditions at inlet and outlets of the artery. We considered coronary circulation is $5 \%$ of the total cardiac output. Generally the cardiac output is $6 \mathrm{l} / \mathrm{min}$, so coronary circulation is $300 \mathrm{ml} / \mathrm{min}$. We have two right coronary outlets for Right Coronary Artery, so the right coronary circulation is distributed equally to these outlets.. For Left Coronary also we have seven outlets, so left coronary circulation also distributed equally.

$$
\text { Inlet (mass flow rate) }=6 \mathrm{l} / \mathrm{min}=1.06 \mathrm{~kg} / \mathrm{s}
$$

Outlets:

$$
\begin{aligned}
& \text { At LCA (mass flow rate) }=250 \mathrm{ml} / \mathrm{min} \\
& \text { RCA (mass flow rate) }=50 \mathrm{ml} / \mathrm{min} \\
& \text { Aortic (pressure) }=100 \mathrm{~mm}-\mathrm{hg} \text {. }
\end{aligned}
$$

At LCA (mass flow rate) $=250 \mathrm{ml} / \mathrm{min}$
Mass flow rate $=1060 \times 0.25 \times \frac{1}{1000 \times 60}=0.004416 \mathrm{~kg} / \mathrm{s}$

Average value of Mass flow rate $=\frac{0.004416}{7}=0.0006308 \mathrm{~kg} / \mathrm{s}$

We gave the average value of Mass flow rate at each Outlet of Left coronary artery.

RCA (mass flow rate) $=50 \mathrm{ml} / \mathrm{min}$

Mass flow rate $=1060 \times 0.05 \times \frac{1}{1000 \times 60}=0.0008333 \mathrm{~kg} / \mathrm{s}$

Average value of Mass flow rate $=\frac{0.0008333}{2}=0.0004164$ $\mathrm{kg} / \mathrm{s}$

We gave the average value of the Mass flow rate at each outlet of Right coronary artery.

\section{Transient State}

For transient state, time dependent boundary conditions were imposed at both outlets. The data of boundary conditions was extracted from plots available using WebPlotDigitizer, a web-based tool to extract data from plots, images and maps. The data was extracted in Microsoft Excel Worksheet (xlsx) format. Then this was converted to Comma Separated Values (.csv), a text file format. These files are imported in to the ANSYS. The inlet boundary condition is constant and it is equal to $0.106 \mathrm{~kg} / \mathrm{s}$. For left coronary artery, for outlet flow rate boundary condition we take average of both LAD and LCX flow rates.

\section{Right coronary outlet mass flow rate graph}

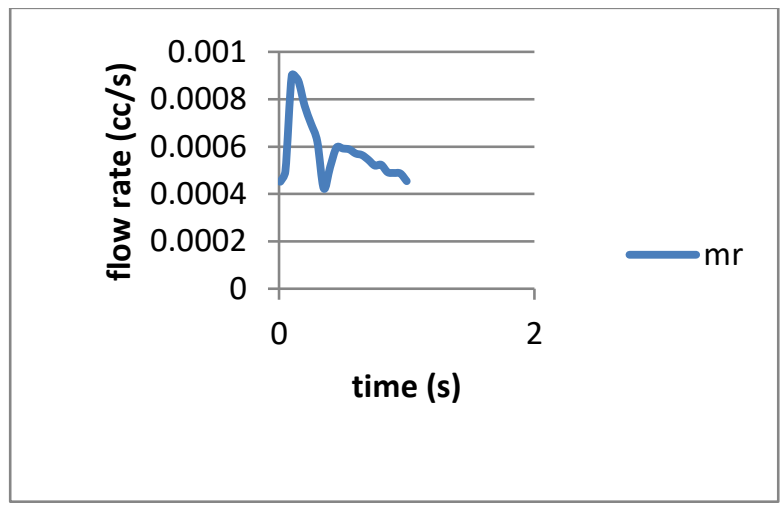

Aorta outlet pressure flow rate graph

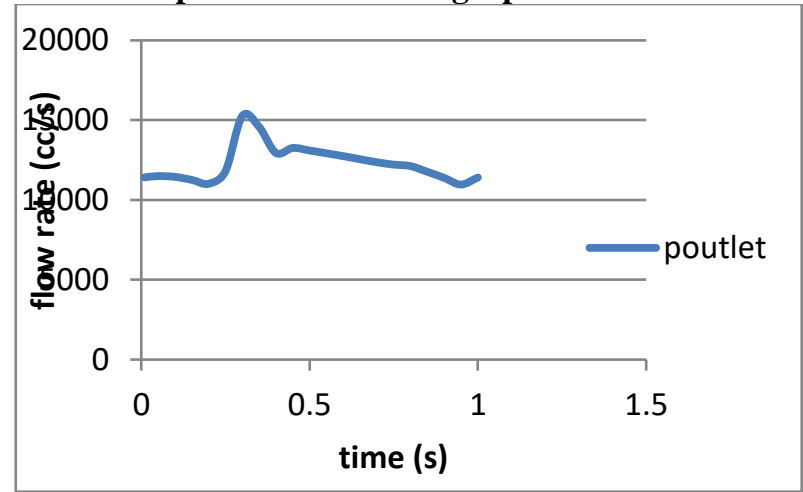


Left coronary outlet mass flow graph

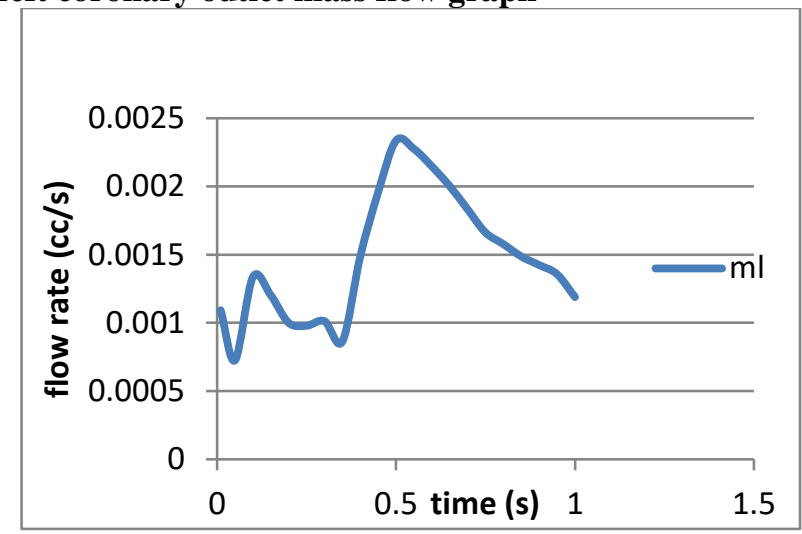

Fig.1.Graphs of Transient boundary conditions

UDF taken as cyclic process, by repeating the same values shown in above graphs up to 25 cycles. These cyclic graphs are shown below

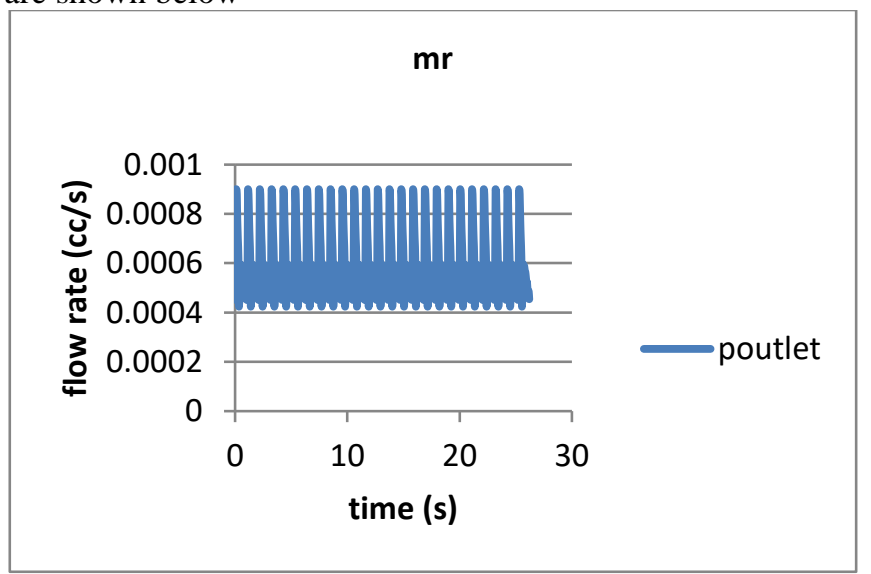

Fig.2.Plot of UDF file with 25 cycles for RCA

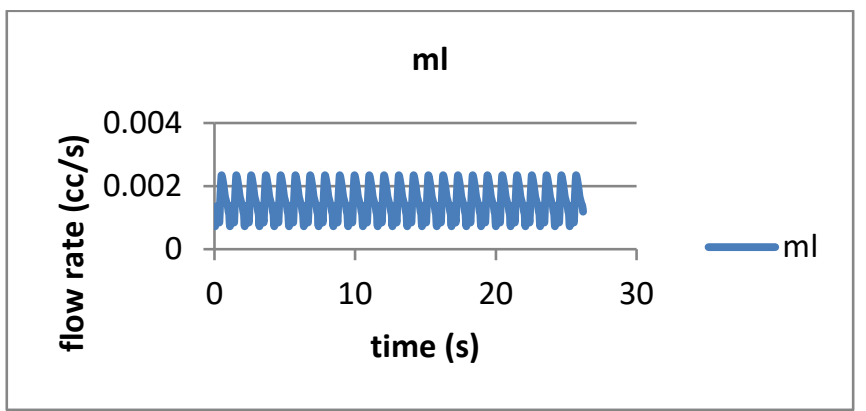

Fig.3.Plot of UDF file with 25 cycles for LCA

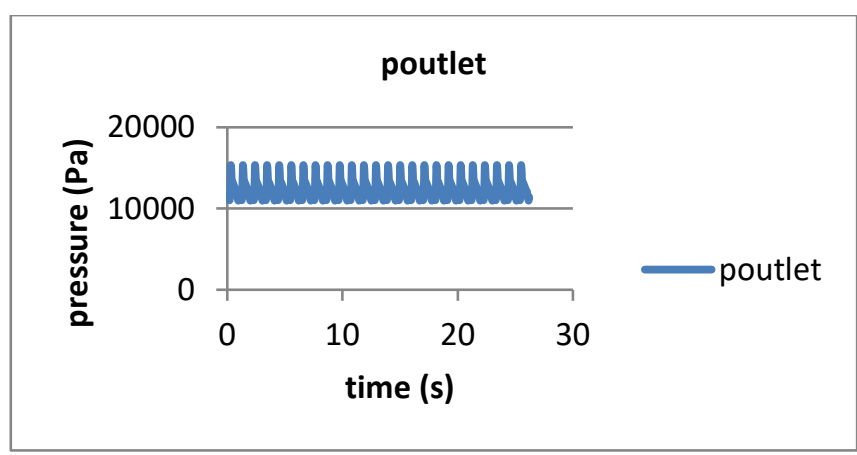

Fig.4.Plot of UDF file with 25 cycles for Aorta

For transient flow analysis, the following data was given to perform calculation for 1 second.
- $\quad$ Time step size $=0.05 \mathrm{~s}$

- $\quad$ Number of time steps $=525$

- $\quad$ Number of iterations per time step $=10$

After the completion of solutions, they were imported to CFD-post for post processing and then results were examined.

\section{RESULTS}

\section{Steady state:}

From the models of steady state there is no change in fluid properties. Boundary conditions as follows, the inlet mass flow rate taken with a rate of $0.106 \mathrm{~kg} / \mathrm{s}$ and aorta outlet taken with $100 \mathrm{mmhg}$ pressure and LCA outlets taken with mass flow rate at each outlet $0.0006308 \mathrm{~kg} / \mathrm{s}$ and RCA outlets taken with mass flow rate at each outlet is $0.0004164 \mathrm{~kg} / \mathrm{s}$.

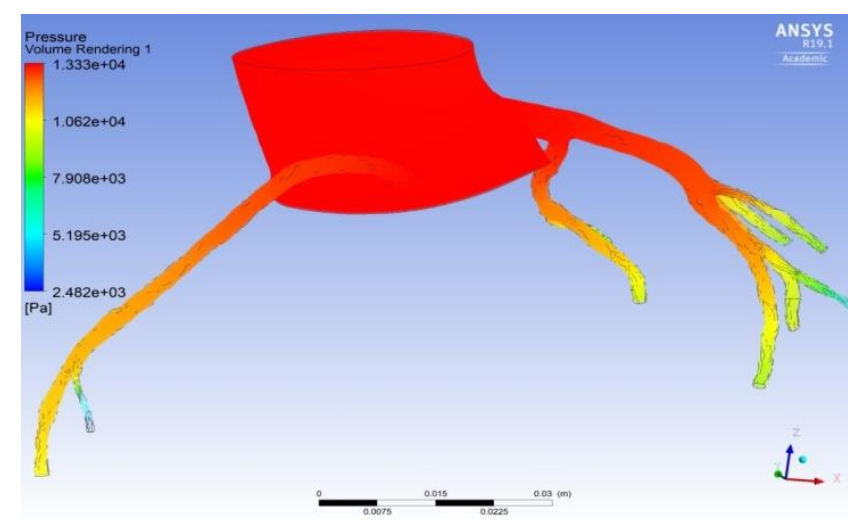

Fig.7. Pressure distribution through the coronary artery

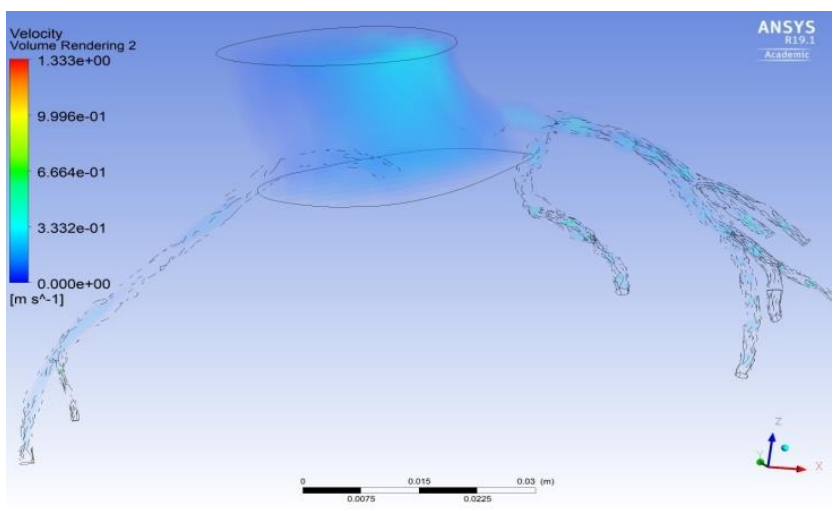

Fig.8 .Velocity distribution through the coronary artery Transient state:

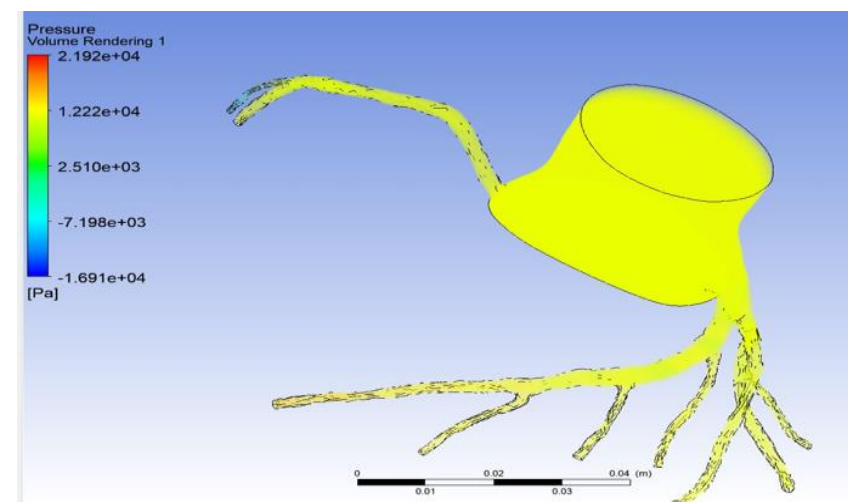

Fig.9. Pressure distribution through the coronary artery

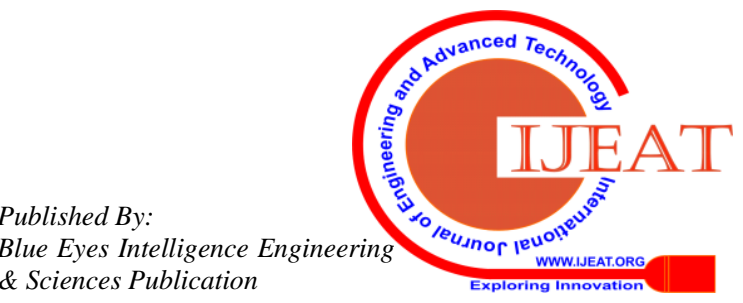




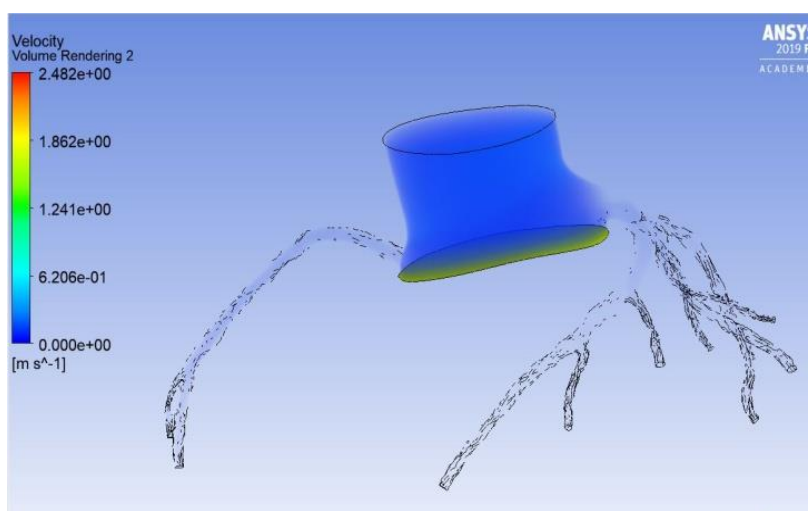

Fig. 10. Volume rendering taking Pressure as variable at 0.05 time step

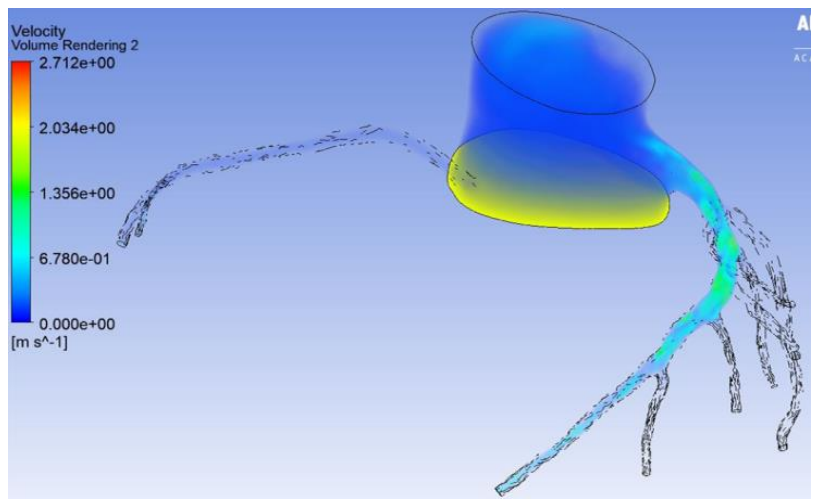

Fig.11.Volume rendering taking Velocity as variable at 20 time step

\section{DISCUSSION}

\section{Steady state:}

During systole the heart muscle contracts, constricting the coronary heart vessels. This is due to a strong contraction particularly from the left ventricle which compresses the intramuscular vessels. During Diastole the cardiac muscle relaxes, enabling blood to flow through the capillaries with no obstruction. In diastole the blood flows rapidly through the capillaries, providing the heart with nutrition. The right ventricle has far less force of contraction compared to the left ventricle therefore the right side ha less phasic changes to the blood flow compared to the left side. The solutions are run until the relative pressure fields at the inlet and outlets did not change more than $1.0 \%$.

Plaque formation in artery can cause decrease in the luminal section of artery. When the blood is flowing to these arteries due to the decrease in area of arteries the pressure and velocity increases. The maximum pressure obtained is $1.333 \mathrm{e}+04 \mathrm{~Pa}$, it is almost equal to average outlet aorta pressure. We observed the maximum pressure at aorta region and at the left coronary and right coronary artery entrance. The maximum pressure occurred at bat bifurcations of artery. The fig 3.12 shows Volume rendering is taken with pressure as variable and observes the distribution of pressure through the artery. When we observed the mass flow, the flow rate of blood is restricted through left coronary artery and right coronary artery due to the plaque formation in artery. The velocity range in LAD and LCX is from 0.3336 $\mathrm{m} / \mathrm{s}$ to $0.6671 \mathrm{~m} / \mathrm{s}$.

\section{Transient state:}

During transient state, Volume rendering is taken with pressure and velocity as variables and we observe the distribution of pressure and velocity through the artery. Time dependent boundary conditions applied at all outlets and observed the pressure distribution, the maximum pressure obtained is $2.192 \mathrm{e}+04 \mathrm{~Pa}$. The pressure increases in left coronary artery and right coronary artery from $2.510 \mathrm{e}+03 \mathrm{~Pa}$ to $1.222 \mathrm{e}+04 \mathrm{~Pa}$. We can observe the pressure $1.222 \mathrm{e}+04 \mathrm{~Pa}$ in aorta region in fig.10. We can observe mass flow rate of blood is decreasing when it passes through left and right coronary arteries. Due to the plaque formation in artery the velocity of blood increase and the velocity increase in left artery and right artery is up to $0.6780 \mathrm{~m} / \mathrm{s}$.

The fig 11 shows the velocity distribution through artery at 20 time step. Volume rendering is taken with velocity as variable and observes the distribution of velocity through the artery. Due to the plaque formation in artery the velocity of blood increase and the velocity increase in left artery from $0.6780 \mathrm{~m} / \mathrm{s}$ to $1.356 \mathrm{~m} / \mathrm{s}$. In right coronary artery we observe the range up to $0.6780 \mathrm{~m} / \mathrm{s}$. The velocity of blood high in left artery compared to right artery because it has more complex geometry. We can observe the highest velocity $2.72 \mathrm{~m} / \mathrm{s}$ in left coronary artery.

\section{CONCLUSION}

Hemodynamic parameters such as velocity magnitude, pressure are obtained on CFD analysis for coronary artery. Non-Newtonian model was simulated using the Power law model. In the stenosis region of artery, velocity magnitude, pressure are found to be higher because blood flow area is reduced. This indicates the presence of plaque in the artery. Though many studies and research were carried out on arteries yet it remained as a challenging task to understand its physiology and working. The main objective of this project is to study the flow behavior and to facilitate a better understanding for further studies on arteries. We take cardiac output as $6 \mathrm{l} / \mathrm{min}$ and considered coronary circulation as $5 \%$ of cardiac output. The amount of coronary circulation in Left coronary artery $250 \mathrm{ml} / \mathrm{min}$ and Right coronary artery $50 \mathrm{ml} / \mathrm{min}$ balances the out flow aorta pressure. This 300 $\mathrm{ml} / \mathrm{min}$ is converted into mass flow rate and velocity for our studies and the results thus obtained are satisfactory.

The flow patterns in a blocked artery was studied and reported in the preceding sections. An important observation made in this project is because of plaque, the blood pressure keeps on increasing. This implies that the heart must pump blood at higher pressure as the artery gets blocked. Due to the plaque formation in artery the diameter of the artery decreases due to this the volume flow rate of blood decreases. During the steady state the maximum pressure obtained is $1.333 \mathrm{e}+04$ it is almost equal to average aorta outlet pressure and the maximum velocity obtained is $1.334 \mathrm{~m} / \mathrm{s}$.

UDF files are used in time varying problems and to get the optimum and realistic solutions. These UDF files with time varying flow rate and pressure are used to give the velocity values at each and every time step .The maximum pressure obtained is $2.192 \mathrm{e}+04 \mathrm{~Pa}$ sand the maximum velocity is $2.712 \mathrm{~m} / \mathrm{s}$ at 20 time step. 


\section{D Transient CFD Modelling of Blood Flow through Coronary Artery}

Compared to RCA, in left coronary artery the flow rate of blood is less because of its diameter and due to reduction in area the velocity of blood increases. It is the one of the cause for the Heart stoke.

While there are medical imaging techniques to visualize flow in arteries, such detailed study of the blood flow cannot be done using those. In such circumstances, Computational Fluid Dynamics can be very helpful to understand the dynamics of blood flow inside the artery.

\section{ACKNOWLEDGEMENT}

The author thanks Principal and Executive Director of Sreenidhi Institute of Science \& Technology for providing necessary facilities to carry out this work in the institution.

\section{REFERENCES:}

1. Friedman, M.H., Deters, O.J., et al. (1983). "Blood vessel geometry influences hemodynamics. A potential hazard factor for athersoclerosis." Atherosclerosis 46(2): 225-231.

2. Zhou, Y., Kassab, G.S. also, Molloi, S.," On the structure of the coronary blood vessel tree: A speculation of Murrayees law.", Phys Med Biol,1999 Dec;44(12):2929-45.

3. Asakura, T. also, Karino, T. (1990). "Stream designs and spatial dispersion of atherosclerotic sores in human coronary courses." Circ Res 66(4): 1045-1066

4. Andrew, C, "Atherosclerosis-The future test of Europe's Health Economics" European Cardiology, 2010;5(2):86-8.

5. B.M. Johnston, P.R. Johnson, S. Corney, and D.Kilpatrick, "Non-Newtonian blood stream in human right coronary supply routes: unfaltering state recreations," Journal of Biomechanics, 37;709-720(2004).

6. 6.ComputationalFluid Dynamics Analysis of the Effect of Plaques in the Left Coronary Artery, Thanapong Chaichana, Zhonghua Sun, James Jewkes.

7. Impact of model limit conditions on blood stream designs in a patient explicit stenotic right coronary supply route, Biyue Liu, Jie Zheng, Richard Bach and Dalin T

8. Liquid Mechanics, third release, Yunus A. Cengel, John M. Cimbala, McGraw Hill Education, 2015.

9. Richter, Y., Groothuis, A., Seifert, P., Edelman, E.R." Dynamic stream adjustments direct leukocyte grip and reaction to endovascular mediations.", 2004 June.

10. Shaaban, A.M., Duerinckx, A.J., "Divider Shear Stress and Early Atherosclerosis: A Review", AJR:174, June 2000.

11. Wahle, A., Prause, G.P.M., DeJon, S.C., Sonka, M., "Geometrically right 3-D reproduction of intravascular ultrasound pictures by combination with biplane angiography- - techniques and approval." IEEE Trans Med Imaging 1999, 18(8): 686-699.

12. Zarins, C.K., Giddens, D.P., Bharadvaj, B.K., Sottiurai, V.S., Mabon, R.F., Glagov, S., "Carotid bifurcation atherosclerosis. Quantitative connection of plaque restriction with stream speed profiles and divider shear pressure."- Circ. Res. 1983; Vol. 53;502-514.

13. Geometry: https://3dprint.nih.gov/find/3dpx-003333

14. Johnson P.R., Kilpatrick D. (1991) Mathematical displaying of move through an unpredictable blood vessel stenosis, Journal of Biomechanics 24, 1069-1077.

15. Geometry: https://3dprint.nih.gov/discover/3dpx-003333.

\section{AUTHORS PROFILE}

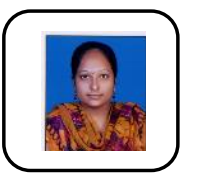

Lakumarapu Veena, has completed her Bachelor of Technology (B.Tech) in Mechanical Engineering from SRTIST Engineering College, Nalgonda; presently she is pursuing her master degree (M.tech) in THERMAL ENGINEERING from Sreenidhi institute of science and technology, Telangana. She completed her M.Tech project work in collaboration with esteemed Associate

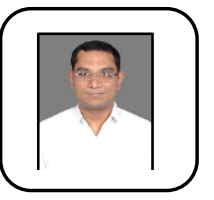

Professor Dr.K.Sai Krishna, Presently he is an Associate Professor of Mechanical Engineering at Sreenidhi Institute of Science \& Technology (SNIST) Hyderabad ,Telangana.

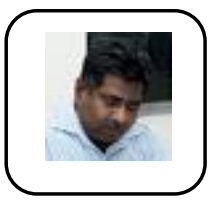

Dr.T.CH.Siva Reddy, He is a Professor, of Mechanical Engineering, HOD of Mechanical engineering. And principal of Sreenidhi institute of science and technology, Hyderabad, Telangana. 